\title{
Perbandingan Model Black Scholes dan Brennan Schwartz untuk Menentukan Harga American Option
}

\author{
Endah Rokhmati MP, Lukman Hanafi, Supriati \\ Jurusan Matematika \\ FMIPA ITS Surabaya \\ endahrmp@matematika.its.ac.id
}

\begin{abstract}
Abstrak
Option adalah kontrak yang memberikan hak kepada pemegang kontrak itu untuk call (membeli) atau put (menjual) suatu underlying asset (aset dasar) dengan exercise price/strike price (harga tertentu) sebelum atau saat expiration date (jangka waktu tertentu). Ada dua macam gaya melakukan exercise, yaitu European Option dan American Option. American option lebih berharga dari pada European option. Proses mendapatkan nilai pada American option termasuk free boundary value problem. Untuk menentukan harga American option digunakan model Black Scholes dan Brennan Schwart. Model tersebut diperoleh dengan menggunakan metode beda hingga. Metode beda hingga yang digunakan adalah metode eksplisit. Dari kedua model tersebut akan dibandingkan berdasarkan kestabilan, akurasi, dan konvergensi. Berdasarkan hasil perbandingannya, berdasarkan kestabilan, kedua model tersebut stabil, berdasarkan akurasi model pendiskritan langsung lebih akurat sampai $94.68 \%$, sedangkan berdasrkan konvergensi model Brennan Schwartz lebih cepat konvergen.
\end{abstract}

Kata Kunci: option, American put option, Black Scholes, Brennan Schwart, eksplisit 


\section{Pendahuluan}

Option adalah kontrak yang memberikan hak kepada pemegang kontrak itu untuk call (membeli) atau put (menjual) suatu underlying asset (aset dasar) dengan strike price (harga tertentu) saat expiration date (jangka waktu tertentu)[7]. Ada dua macam gaya mengexercise option, yaitu European Option dan American Option[7]. European Option, option hanya dapat diexercise tepat pada saat expiration date. Sedangkan American Option, option dapat diexercise sewaktu-waktu sampai batas expiration date[1]. Perbedaan itulah yang menyebabkan American Option lebih berharga dari pada European Option. Proses mendapatkan nilai pada American option termasuk free boundary value problem[4]. Umumnya solusi analitik tidak dapat digunakan pada American option, kecuali tipe khusus yaitu American call dengan pembayaran aset deviden[4]. Selain itu solusi analitik cenderung lebih sulit dari pada pendekatan secara numerik dengan memakai finite difference (bedahingga)[2]. Harga American Option diperoleh dari model Black Scholes (model pendiskritan langsung) dan Brennan Schwartz. Model tersebut diselesaikan dengan metode eksplisit yang merupakan salah satu bagian dari metode beda hingga.

\section{American Option}

Seperti yang dijelaskan diatas, bahwa American Option adalah option yang dapat diexercise sewaktu-waktu (early exercise) sampai expiration date. Oleh karena itu, American option lebih berharga dari pada European option. Nilai pada European option lebih kecil dari pada payoffnya[8]. Nilai pada European option lebih kecil dari pada payoffnya[8]. Hal ini tidak terjadi pada American option, misal American put option mempunyai nilai dimana seseorang dapat memperoleh keuntungan dengan cara mengexercise secara serentak, yaitu dengan membeli aset dan put[8], sedangkan nilai American call option bernilai $V_{C}^{a m}<(K-S)^{+}[2]$. Hal ini tidak boleh dilakukan Sehingga pada American option berlaku

$$
V_{p}^{a m}(S, t) \geq(K-S)^{+} \quad \text { untuk } \forall(S, t)
$$

Ilustrasi tersebut jika digambarkan adalah seperti yang tersebut pada Gambar 1.

Pada Gambar 1 terlihat bahwa payoff American option $V_{P}(S t, t)$ lebih tinggi dari pada nilai European option $V_{E P}(S t, t)$. Kondisi tersebut terjadi ketika early exercise optimal[2]. Early exercise berarti nilai $V$ dan $S$ diserahkan dan nilai $K$ diterima, dengan kata lain $K-V-S$ merupakan keuntungan yang diperoleh.

Pada Persamaan 1 American option memenuhi $V_{P}(S, t) \equiv K-S$ untuk $S>0$. Di sisi lain $V_{p}^{a m} \geq(K-S)^{+}$. $V_{P}$ menjelaskan nilai $S_{f}$ dengan $0<S_{f}<K$. 


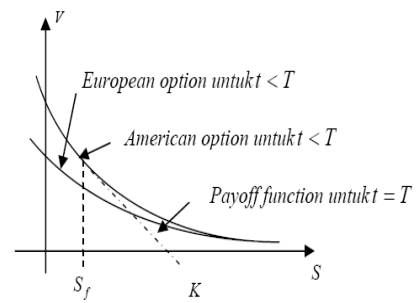

Gambar 1: Grafik $V(S, t)$ untuk Put Option

Sehingga fungsi payoff dapat dicapai $V_{p}^{a m}\left(S_{f}, t\right)=\left(K-S_{f}\right)^{+}$. Nilai $S_{f}$ bergantung dengan $t$, sehingga $S_{f}=S_{f}(t)$. Sehingga dapat ditulis

$$
\begin{array}{lll}
V_{p}^{a m}\left(S_{f}, t\right)>\left(K-S_{f}\right)^{+} & \text {untuk } & S>S_{f}(t) \\
V_{p}^{a m}\left(S_{f}, t\right)=\left(K-S_{f}\right)^{+} & \text {untuk } & S \leq S_{f}(t)
\end{array}
$$

Proses mendapatkan nilai $V_{p}^{a m}$ untuk $S>S_{f}(t)$ termasuk free boundary value problem[5]. Proses mendapatkan nilai $V_{P}$ memenuhi persamaan Black-Scholes sebagai berikut

$$
\frac{\delta V}{\delta t}+r S \frac{\delta V}{\delta S}+\frac{1}{2} \sigma^{2} S^{2} \frac{\delta^{2} V}{\delta S^{2}}-r V=0
$$

\section{Model Brennan Schwartz}

Model Brennan Schwartz merupakan perluasan dari persamaan Black Sholes. Dimana model ini menggunakan transformasi log pada stock price $S[5]$. Menggunakan transformasi $\log$ pada $S$ lebih efisien karena ketika $\sigma$ konstan, standart deviasi $\log S$ adalah konstan[5]. Transformasi log pada persamaan Black Scholes sebagai berikut:

$$
\begin{aligned}
Z & =\ln S \\
S & =e^{Z} \\
W(Z, t) & =V(S, t)
\end{aligned}
$$

Sehingga

$$
\begin{aligned}
\frac{\delta V}{\delta S} & =e^{-Z} \frac{\delta W}{\delta Z} \\
\frac{\delta^{2} V}{\delta S^{2}} & =e^{-Z}\left(\frac{\delta^{2} W}{\delta Z^{2}}-\frac{\delta W}{\delta Z}\right) \\
\frac{\delta V}{\delta t} & =\frac{\delta W}{\delta t}
\end{aligned}
$$


Dengan mensubtitusikan Persamaan 3 pada Persamaan 2, maka persamaan Black Scholes menjadi:

$$
\frac{\delta W}{\delta t}+\left(r-\frac{1}{2} \sigma^{2}\right) \frac{\delta W}{\delta Z}+\frac{1}{2} \sigma^{2} \frac{\delta^{2} W}{\delta Z^{2}}-r W=0
$$

\section{Metode Beda Hingga}

Metode beda hingga merupakan salah satu bentuk penyelesaian numerik yang digunakan untuk menyelesaikan persamaan diferensial. Bentuk penyelesaian numerik diperoleh dari deret Taylor

$$
f\left(x_{i+1}\right)=f\left(x_{i}\right)+f^{\prime}\left(x_{i}\right) \Delta x+O(\Delta x)^{2}
$$

Node adalah pembagian media menjadi daerah-daerah kecil. Kumpulan dari node disebut node network atau mesh. Node network digunakan untuk menyelesaian persamaan beda hingga, dimana besar kecilnya jumlah node mempengaruhi ketelitian perhitungan. Titik hitungan pada bidang $t-x$ seperti yang tersebut pada Gambar 2

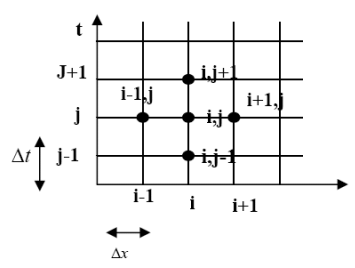

Gambar 2: Node Network pada Pendekatan Beda Hingga

Dengan menggunakan titik $(i, j)$ sebagai titik tinjauan, maka berdasarkan Gambar 2, maka diperoleh persamaan beda hingga sebagai berikut:

Beda maju

$$
\frac{\delta f}{\delta x} \approx \frac{f_{i+1, j}-f_{i, j}}{\Delta x}
$$

Beda mundur

$$
\frac{\delta f}{\delta x} \approx \frac{f_{i, j}-f_{i-1, j}}{\Delta x}
$$

Beda pusat

$$
\frac{\delta f}{\delta x} \approx \frac{f_{i+1, j}-f_{i-1, j}}{2 \Delta x}
$$

Demikian pula diferensiasi fungsi $f$ terhadap $\Delta t$, sehingga 
Beda maju

$$
\frac{\delta f}{\delta t} \approx \frac{f_{i+1, j+1}-f_{i+1, j}}{\Delta t}
$$

Beda mundur

$$
\frac{\delta f}{\delta t} \approx \frac{f_{i+1, j}-f_{i+1, j-1}}{\Delta t}
$$

Beda pusat

$$
\frac{\delta f}{\delta t} \approx \frac{f_{i+1, j+1}-f_{i+1, j-1}}{2 \Delta t}
$$

Kriteria perbandingan yang digunakan meliputi:

a. Kestabilan dengan menggunakan metode von Neumann's,

b. Kekonsistenan dan kekonvergenan

\section{Model Beda Hingga untuk American Option}

Model yang digunakan untuk menentukan harga American put option adalah model pendiskritan langsung dan model Brennan Schwart. Model pendiskritan langsung berarti mendiskritkan persamaan Black Scholes pada Persamaan 2, sedangkan model Brennan Schwartz berarti mendiskritkan persamaan awal Brennan Schwartz pada Persamaan 4.

\section{Model Pendiskritan Langsung}

Metode eksplisit digunakan untuk mendapatkan model pendiskritan langsung untuk fungsi $V(t, S)$ pada titik awal $(t+\Delta t, S)$ dengan titik tinjauan $(t, S)$ dan titik awal $(t, S)$ dengan titik tinjauan $(t-\Delta t, S)$.

Berdasarkan Gambar 3 dan mengacu pada Persamaan 6, 9, dan 11, maka dengan menggunakan beda maju pada titik $(t, S)$ diperoleh:

$$
\left.\frac{\delta V}{\delta t}\right|_{(t, S)}=\frac{V(t+\Delta t, S)-V(t, S)}{\Delta t}+O(\Delta t)
$$

Sedangkan dengan menggunakan beda maju pada titik $(t+\Delta t, S)$ diperoleh diskritisasi untuk

$$
\left.\frac{\delta V}{\delta S}\right|_{(t, S)} \quad \text { dan }\left.\quad \frac{\delta^{2} V}{\delta S^{2}}\right|_{(t, S)}
$$

Beda tengah juga digunakan untuk mendapatkan diskritisasi pada titik $(t+\Delta t, S)$. Diskritisasi tersebut disubstitusikan pada persamaan Black Scholes sehingga diper- 


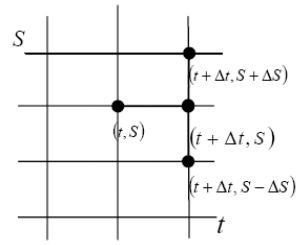

Gambar 3: Grid Beda Maju dengan Titik Tinjauan $(t, S)$

oleh

$$
\begin{aligned}
V(t, S)= & \frac{1}{(1+r \Delta t)}\left\{\left(-\frac{1}{2} \frac{r S \Delta t}{\Delta S}+\frac{1}{2} \frac{\sigma^{2} S^{2} \Delta t}{(\Delta S)^{2}}\right) V(t+\Delta t, S-\Delta S)\right. \\
& +\left(1-\frac{\sigma^{2} S^{2} \Delta t}{(\Delta S)^{2}}\right) V(t+\Delta t, S) \\
& \left.+\left(\frac{1}{2} \frac{r S \Delta t}{\Delta S}+\frac{1}{2} \frac{\sigma^{2} S^{2} \Delta t}{(\Delta S)^{2}}\right) V(t+\Delta t, S+\Delta S)\right\}
\end{aligned}
$$

Dengan mengambil $S=m \Delta S$ dan $V(t, S)=(n \Delta t, m \Delta S)=v_{n}^{m}$, maka diperoleh

$$
v_{n}^{m}=a_{n}^{*} v_{n+1}^{m-1}+b_{n}^{*} v_{n+1}^{m}+c_{n}^{*} v_{n+1}^{m+1}
$$

dengan:

$$
\begin{aligned}
a_{n}^{*} & =\frac{1}{(1+r \Delta t)}\left(-\frac{1}{2} r m \Delta t+\frac{1}{2} \sigma^{2} m^{2} \Delta t\right) \\
b_{n}^{*} & =\frac{1}{(1+r \Delta t)}\left(1-\sigma^{2} m^{2} \Delta t\right) \\
c_{n}^{*} & =\frac{1}{(1+r \Delta t)}\left(\frac{1}{2} r m \Delta t+\frac{1}{2} \sigma^{2} m^{2} \Delta t\right)
\end{aligned}
$$

dengan $n=0,1,2, \cdots, N-1$ dan $m=1,2, \cdots, M-1$.

Jika $n^{-} \leq n \leq n^{+}$dengan nilai minimum $n$ adalah $n^{-}$dan maksimum $n=n^{+}$, dan $m^{-}<m<m^{+}$dengan nilai minimum $m$ adalah $m^{-}$dan maksimum $m=m^{+}$, maka Persamaan 14 dapat ditulis: 
untuk $n=n^{-}$sampai $n=n^{+}$, maka

$$
\begin{aligned}
& a_{n}^{*} v_{n^{-}+1}^{m^{-}-1}+b_{n}^{*} v_{n^{-}+1}^{m^{-}}+c_{n^{*}}^{*} v_{n^{-}+1}^{m^{-}+1}=v_{n^{-}}^{m^{-}} \\
& a_{n}^{*} v_{n^{-}+1}^{m^{-}}+b_{n}^{*} v_{n^{-}+1}^{m^{-}+1}+c_{n}^{*} v_{n^{-}+1}^{m^{-}+2}=v_{n^{-}}^{m^{-}+1} \\
& \text {... } \ldots \\
& a_{n}^{*} v_{n^{-}+1}^{m+1}+b_{n}^{*} v_{n^{-}+1}^{m^{+}}+c_{n}^{*} v_{n^{-}+1}^{m^{+}+1}=v_{n^{-}}^{m^{+}} \\
& \text {... } \ldots \\
& a_{n}^{*} v_{n^{+}+1}^{m^{-}-1}+b_{n}^{*} v_{n^{+}+1}^{m^{-}}+c_{n}^{*} v_{n^{+}+1}^{m^{-}+1}=v_{n^{+}}^{m^{-}} \\
& a_{n}^{*} v_{n^{+}+1}^{m^{-}}+b_{n}^{*} v_{n^{+}+1}^{m^{-}+1}+c_{n}^{*} v_{n^{+}+1}^{m^{-}+2}=v_{n^{+}}^{m^{-}+1} \\
& a_{n}^{*} v_{n^{+}+1}^{m+1}+b_{n}^{*} v_{n^{+}+1}^{m^{+}}+c_{n}^{*} v_{n^{+}+1}^{m^{+}+1}=v_{n^{+}}^{m^{+}}
\end{aligned}
$$

Metode eksplisit dengan titik tinjauan $(t-\Delta t, S)$ diperoleh dengan cara yang sama dan menghasilkan

$$
v_{n-1}^{m}=a_{n}^{*} v_{n}^{m-1}+b_{n}^{*} v_{n}^{m}+c_{n}^{*} v_{n}^{m+1}
$$

dengan

$$
\begin{aligned}
& a_{n}^{*}=\frac{1}{(1+r \Delta t)}\left(-\frac{1}{2} r n \Delta t+\frac{1}{2} \sigma^{2} n^{2} \Delta t\right) \\
& b_{n}^{*}=\frac{1}{(1+r \Delta t)}\left(1-\sigma^{2} n^{2} \Delta t\right) \\
& c_{n}^{*}=\frac{1}{(1+r \Delta t)}\left(\frac{1}{2} r n \Delta t+\frac{1}{2} \sigma^{2} n^{2} \Delta t\right)
\end{aligned}
$$

dengan $n=1,2, \cdots, N-1$ dan $m=1,2, \cdots, M-1$.

Dari kedua model tersebut, model pendiskritan langsung dengan titik tinjauan $(t, S)$ dan $(t-\Delta t, S)$ boundary conditionnya (BC) adalah saat waktu $T$ adalah $\max [K-S T, 0]$, dimana $S_{T}$ adalah stock price, pada saat $T$. Sehingga:

$$
\begin{aligned}
V_{N}^{m} & =\max [K-m S, 0] \\
N & =-\Delta \text { untuk setiap } m=0,1, L, M
\end{aligned}
$$

Nilai option adalah $K$ pada saat harga saham nol, sehingga:

$$
V_{n}^{0}=K, \quad \text { untuk setiap } \quad n=0,1,2, \cdots, N
$$

Sedangkan nilai option adalah nol untuk $S=S_{\max }$, sehingga:

$$
V_{n}^{M}=0, \quad \text { untuk setiap } \quad n=0,1,2, \cdots, N
$$




\section{Model Brennan Schwart}

Metode eksplisit digunakan untuk mendapatkan model Brennan Schwartz untuk fungsi $W(t, Z)$ pada titik awal $(t+\Delta t, Z)$ dengan titik $(t, Z)$ sebagai titik tinjauan dan titik awal $(t, Z)$ dengan titik tinjauan $(t-\Delta t, Z)$. Model pendiskritan untuk titik $(t, Z)$ sebagai titik tinjauan diperoleh

$$
\begin{aligned}
W(t, Z)= & \frac{1}{(1+r \Delta t)}\left[\left\{-\frac{\Delta t}{2 \Delta Z}\left(r-\frac{1}{2} \sigma^{2}\right)+\frac{\sigma^{2} \Delta t}{2(\Delta Z)^{2}}\right\} W(t+\Delta t, Z-\Delta Z)\right. \\
& +\left(1-\frac{\sigma^{2} \Delta t}{(\Delta Z)^{2}}\right) W(t+\Delta t, Z) \\
& \left.+\left\{\frac{\Delta t}{2 \Delta Z}\left(r-\frac{1}{2} \sigma^{2}\right)+\frac{\sigma^{2} \Delta t}{2(\Delta Z)^{2}}\right\} W(t+\Delta t, Z+\Delta Z)\right]
\end{aligned}
$$

misal $W(t, Z)=(n \Delta t, m \Delta Z)=w_{n}^{m}$ maka diperoleh

$$
w_{n}^{m}=\alpha_{n}^{*} w_{n+1}^{m-1}+\beta_{n}^{*} w_{n+1}^{m}+\gamma_{n}^{*} w_{n+1}^{m+1}
$$

dengan

$$
\begin{aligned}
\alpha_{n}^{*} & =\frac{1}{(1+r \Delta t)}\left\{-\frac{\Delta t}{2 \Delta Z}\left(r-\frac{1}{2} \sigma^{2}\right)+\frac{\sigma^{2} \Delta t}{2(\Delta z)^{2}}\right\} \\
\beta_{n}^{*} & =\frac{1}{(1+r \Delta t)}\left(1-\frac{\sigma^{2} \Delta t}{(\delta Z)^{2}}\right) \\
\gamma_{n}^{*} & =\frac{1}{(1+r \Delta t)}\left\{\frac{\Delta t}{2 \Delta Z}\left(r-\frac{1}{2} \sigma^{2}\right)+\frac{\sigma^{2} \Delta t}{2(\Delta z)^{2}}\right\}
\end{aligned}
$$

dengan $n=0,1,2, \cdots, N-1$ dan $m=1,2, \cdots, M-1$.

Dengan cara yang sama didapat pendiskritan dengan titik tinjauan $(t-\Delta t, Z)$ yaitu

$$
w_{n-1}^{m}=\alpha_{n}^{*} w_{n}^{m-1}+\beta_{n}^{*} w_{n}^{m}+\gamma_{n}^{*} w_{n}^{m+1}
$$

dengan

$$
\begin{aligned}
\alpha_{n}^{*} & =\frac{1}{(1+r \Delta t)}\left\{-\frac{\Delta t}{2 \Delta Z}\left(r-\frac{1}{2} \sigma^{2}\right)+\frac{\sigma^{2} \Delta t}{2(\Delta z)^{2}}\right\} \\
\beta_{n}^{*} & =\frac{1}{(1+r \Delta t)}\left(1-\frac{\sigma^{2} \Delta t}{(\delta Z)^{2}}\right) \\
\gamma_{n}^{*} & =\frac{1}{(1+r \Delta t)}\left\{\frac{\Delta t}{2 \Delta Z}\left(r-\frac{1}{2} \sigma^{2}\right)+\frac{\sigma^{2} \Delta t}{2(\Delta z)^{2}}\right\}
\end{aligned}
$$

dengan $n=1,2, \cdots, N-1$ dan $m=1,2, \cdots, M-1$. 
Dari kedua model tersebut, model Brennan Schwartz dengan titik tinjauan $(t, Z)$ dan $(t-\Delta t, Z)$ boundary conditionnya (BC) adalah saat waktu $T$ adalah $\max \left[K-Z_{T}, 0\right]$, dimana $Z_{T}$ adalah stock price, pada saat $T$. Sehingga:

$$
Z_{N+1}^{m}=\max [K-\exp \{Z 0+m(\Delta Z)\}, 0] \quad \text { untuk setiap } m=0,1, \cdots, M
$$

Nilai option adalah $K$ pada saat harga saham nol, sehingga:

$$
Z_{n}^{0}=K \quad \text { untuk setiap } n=0,1,2, \cdots, N
$$

Sedangkan nilai option adalah nol untuk $Z=Z_{\max }$, sehingga:

$$
Z_{n}^{M}=K \quad \text { untuk setiap } n=0,1,2, \cdots, N
$$

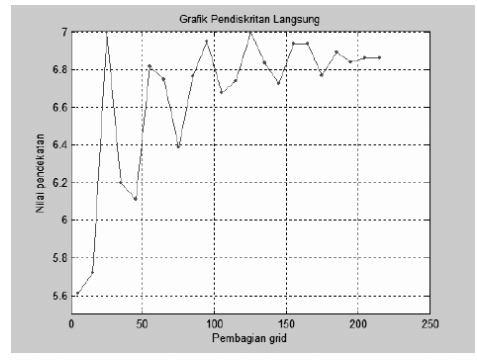

Gambar 4: Grafik Model Pendiskritan langsung

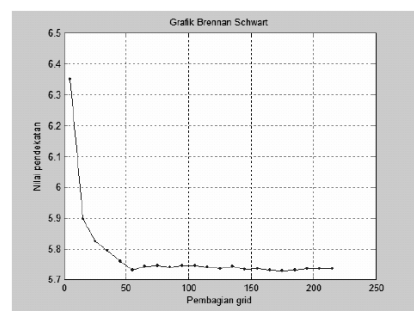

Gambar 5: Grafik Model Brenann Schwartz

\section{Hasil Simulasi}

Model pendiskritan langsung dengan memasukkan batas $n$ dan $m$, baik dengan titik tinjauan $(t, S)$ maupun $(t-\Delta t, S)$ menghasilkan koefisien matrik yang sama, maka untuk simulasinya digunakan persamaan hasil pendiskritan dengan titik tinjauan $(t, S)$. Hal ini juga berlaku untuk model Brennan Schwartz. Untuk mempermudah perhitungan digunakan data. Data tersebut dibangkitkan dari MATLAB 6.5. Untuk model pendiskritan langsung datanya adalah $S=50, S_{\max }=100$, $K=55$, vol $=0.3, r=0.1, T=5 / 12$, sedangkan model Brennan Schwartz $S=50, K=55, S_{\max }=100, Z=\log (S), Z_{\max }=\operatorname{round}(\log (\operatorname{Smax}))$, vol $=0.3$, $r=0.1, T=5 / 12$. Dari hasil runningnya dapat dilihat bahwa nilai sebenarnya baik dengan menggunakan model pendiskritan langsung maupun model Brennan Schwartz adalah 7.0284, sedangkan nilai pendekatan dan error dari masing-masing model seperti yang tersebut pada Tabel 1. 
Tabel 1: Nilai Pendekatan dan Error dengan Menggunakan Model Pendiskritan Langsung

\begin{tabular}{|c|c|c|c|c|}
\hline \multirow[b]{3}{*}{$\operatorname{Grids}(\mathrm{n})$} & \multicolumn{2}{|c|}{ Model Pendiskritan } & \multicolumn{2}{|c|}{ Model Brenann Schwartz } \\
\hline & \multicolumn{2}{|c|}{ Langsung dengan Metode Eksplisit } & \multicolumn{2}{|c|}{ dengan Metode Eksplisit } \\
\hline & $\begin{array}{c}\text { nilai } \\
\text { pendekatan }\end{array}$ & error & $\begin{array}{c}\text { nilai } \\
\text { pendekatan }\end{array}$ & error \\
\hline 5 & 5.6312 & 1.4152 & 6.0194 & 1.2949 \\
\hline 15 & 5.7235 & 1.3049 & 5.8516 & 1.1768 \\
\hline 25 & 7.0000 & 0.0284 & 5.7605 & 1.2679 \\
\hline 35 & 6.1997 & 0.8287 & 5.7632 & 1.2652 \\
\hline 45 & 6.1111 & 0.2102 & 5.7424 & 1.2861 \\
\hline 55 & 6.8182 & 0.2793 & 5.7167 & 1.3117 \\
\hline 65 & 6.7491 & 0.6383 & 5.7312 & 1.2972 \\
\hline 75 & 6.3902 & 0.2637 & 5.7359 & 1.2926 \\
\hline 85 & 6.7647 & 0.0768 & 5.7331 & 1.2953 \\
\hline 95 & 6.9516 & 0.3525 & 5.7335 & 1.2916 \\
\hline 105 & 6.6759 & 0.2893 & 5.7377 & 1.2907 \\
\hline 115 & 6.7391 & 0.0284 & 5.7346 & 1.2939 \\
\hline 125 & 7.0000 & 0.1938 & 5.7297 & 1.2987 \\
\hline 135 & 6.8346 & 0.3043 & 5.7371 & 1.2913 \\
\hline 145 & 6.7241 & 0.0929 & 5.7294 & 1.2990 \\
\hline 155 & 6.9355 & 0.0928 & 5.7322 & 1.2962 \\
\hline 165 & 6.9356 & 0.2573 & 5.7272 & 1.3012 \\
\hline 175 & 6.7711 & 0.1365 & 5.7261 & 1.3023 \\
\hline 185 & 6.8919 & 0.1863 & 5.7287 & 1.2997 \\
\hline 195 & 6.8421 & 0.1667 & 5.7326 & 1.2958 \\
\hline 205 & 6.8617 & 0.1679 & 5.7338 & 1.0091 \\
\hline 215 & 6.8605 & 0.4152 & 5.7368 & 1.2946 \\
\hline
\end{tabular}


Berdasarkan Tabel 1, tampak error dari masing-masing model adalah $\xi_{1}=$ $5.32 \%$ error model pendiskritan langsung, tingkat akurasi $94.68 \%$, dan $\xi_{2}=17.25 \%$ error model Brennan Schwartz, dengan tingkat akurasi $82.25 \%$. Karena model pendikritan langsung mempunyai error lebih kecil dari pada model Brennan Schwartz, maka dapat disimpulkan bahwa model pendiskritan langsung lebih akurat.

Jika dibuat grafik hubungan nilai pendekatan dan pembagian grid dapat dilihat pada Gambar 4 untuk model pendiskritan langsung dan Gambar 5 untuk model Brennan Schwartz maka bisa disimpulkan bahwa nilai pendekatan dari model pendiskritan langsung mendekati nilai tertentu, yaitu 6,86. Hal ini berarti bahwa model pendiskritan langsung konvergen pada 6,86 . Nilai pendekatan dari model Brennan Schwartz mendekati nilai tertentu, yaitu 5,73. Hal ini berarti bahwa model Brennan Schwartz konvergen pada 5, 73.

\section{Kesimpulan}

Berdasarkan pembahasan diatas tentang model pendiskritan langsung dan Brennan Schwart untuk menentukan harga American Option, dapat disimpulkan bahwa:

a. Model pendikritan langsung dengan titik tinjauan $(t, S)$ dan $(t-\Delta t, S)$ stabil pada $0 \leq \xi \leq 1$ untuk $-1<r \Delta t \leq 0$, dan

$$
\left[1-\left(\sigma^{2} S^{2} \lambda\right)+\left(\frac{\sigma^{2} S^{2}}{2} \lambda\right)\right]^{2}+\left[\left(\frac{r S \Delta t}{2 \Delta S}\right) 2 \sin (q \Delta S)\right]^{2} \geq 1
$$

b. Model Brennan Schwartz dengan titik tinjauan $(t, Z)$ dan $(t-\Delta t, Z)$ stabil pada $0 \leq \xi \leq 1$ untuk $-1<r \Delta t \leq 0$, dan

$$
\left[1-\sigma^{2} \varphi+\left(\frac{\sigma^{2}}{2}\right) 2 \cos q \Delta Z\right]^{2}+\left[\frac{\Delta t}{2 \Delta Z}\left(r-\frac{1}{2} \sigma^{2}\right) 2 \sin (q \Delta Z)\right]^{2} \geq 1
$$

c. Berdasarkan akurasi, model pendiskritan langsung lebih akurat dengan tingkat akurasi sampai $94.68 \%$.

d. Berdasarakan konvergensi, model Brennan Schwartz lebih konvergen.

\section{Pustaka}

[1] Hull, C. 2002. Option Future and Other Derivatives. Prentice Hall, New Jersey. 
[2] Kerman, Jouni. 2002. Numerical Method for Option Pricing: Binomial and Finatte-difference Aproximation. New York.

[3] Kusumaningtyas, Khoriyati. 2007. Estimasi Harga American Put Option Tanpa Deviden Menggunakan Metode Binomial. Tugas Akhir. ITS.

[4] Kwok, Yue-kuen. 1998. Mathematical Models of Financial Derivarives. Springer.

[5] Leveque. J, Randall. 2006. Finite Difference Methods for Differential Equations.

[6] Seydel, Rudiger. 2002. Tools Computational Finance. Springer. New York.

[7] Smith, G.D. 1985. Numerical Solution of Partial Differential Equations: Finite Difference Methods. Oxfor University Press. New York.

[8] Sukha, Shamer. 2001. Finite-Difference Methods for Pricing the American Put Option. 